\title{
Pengembangan Sistem Kendali Robot Humanoid untuk Edukasi berdasarkan Robosapien dan Raspberry Pi Zero
}

\author{
Heri Ngarianto $^{1}$, Alexander A S Gunawan ${ }^{2}$ \\ ${ }^{1,2}$ Computer Science Department, School of Computer Science, \\ Bina Nusantara University, \\ Jakarta, Indonesia 11480 \\ heri.nganrianto@binus.ac.id; \\ aagung@binus.edu
}

\begin{abstract}
In order to help students be more interested in learning about programming both at school and at home, we have designed educational toys in the form of humanoid robot. In this paper, intelligent robot movement control systems are developed, thus the students can interact directly and learn programming on human robots. For building a low-cost humanoid robot, we modified low-cost robot toy, that is Robosapien from Wowwee by embbeding a control system. The control system is developed based on Raspberry Pi Zero W, which enables us to control Robosapien's movements wirelessly. This learning media is expected to enhance the student's spirit of learning, especially in the field of robotics and programming. The main contribution of the research is the description and analysis of various design decisions during the development of this humanoid robot. In addition, it provides information about the main components for development and example for interacting with robots as learning media.
\end{abstract}

Keywords: Learning media; Humanoid robot; Robosapien; Raspberry Pi Zero W; Python

\footnotetext{
Abstrak - Untuk membantu siswa lebih tertarik untuk belajar tentang teknologi terutama untuk pemrograman baik di sekolah maupun di rumah, kami telah merancang mainan pendidikan yang berupa robot manusia. Dalam makalah ini, dikembangkan sistem kendali pergerakan robot cerdas sehingga siswa dapat berinteraksi langsung dan mempelajari pemrograman pada robot manusia. Agar dapat membangun robot ini dengan biaya rendah, maka kami memodifikasi Robosapien dari Wowwee dengan menanamkan sebuah sistem kendali. Dengan sistem kendali yang dibangun menggunakan Raspberry Pi Zero $W$, kita dapat mengendalikan gerakan robot manusia secara nirkabel. Media pembelajaran ini diharapkan dapat mendongkrak semangat belajar siswa, khususnya di bidang robotika dan pemrograman. Kontribusi utama dari penelitian ini adalah penjelasan dan analisis dari berbagai
}

keputusan desain selama pengembangan robot manusia ini. Selain itu, memberikan informasi tentang komponen utama yang dibutuhkan dan contoh untuk berinteraksi dengan robot sebagai media pembelajaran.

Kata Kunci: Media pembelajaran; Robot manusia; Robosapien;Raspberry Pi Zero W; Python

\section{PENDAHULUAN}

Belajar pemrograman merupakan suatu hal yang sulit bagi pemula. Hal ini terbukti dengan tingginya kegagalan dalam mata pelajaran pemrograman di tingkat awal atau hanya menghasilkan sedikit kemajuan dalam menguasai ketrampilan pemrograman pada pemula (Major, 2012). Dalam beberapa tahun terakhir, robot telah menembus bidang pendidikan, baik sebagai alat untuk memotivasi siswa mengeksplorasi rekayasa teknologi sains dan pemrograman. Robot pendidikan harus mempunyai fitur untuk berinteraksi dengan manusia, sehingga robot humanoid sering menjadi pilihan utama sebagai robot pendidikan. Robot humanoid ini dapat digunakan untuk memotivasi dan memfasilitasi materi yang mendasar, seperti pemrograman komputer, kecerdasan buatan atau desain teknik (Miller, 2016). Saat ini, teknologi robot humanoid sudah berkembang pesat. Robot humanoid ini banyak digunakan di berbagai bidang seperti edukasi, kesehatan, hiburan, industri, dan keamanan negara. Khusus dibidang edukasi, robot humanoid mempunyai keunggulan dalam proses interaksi langsung dengan manusia (Pandey, 2017). Robot humanoid yang memiliki penampilan mirip dengan manusia, dapat dilengkapi dengan kemampuan interaksi multimodal sehingga dapat berinteraksi dengan manusia melalui bahasa dan gerakan tubuh.

Selama terdapat pengalaman yang belum memuaskan dalam penggunaan teknologi, maka akan muncul inovasi yang lebih baru untuk menutupi kekurangan dari teknologi ini. Salah satu teknologi yang terus dikembangkan saat 
ini adalah robot. Penggunaan robot di bidang pendidikan, menuntut kebutuhan robot harus dapat berinteraksi seperti layaknya manusia (Ospennikovaə, 2015). Di Indonesia, telah banyak bermunculan lembaga pendidikan yang mengajar siswa usia 4 - 18 tahun untuk mempelajari bidang robotika. Fenomena ini, membuktikan bahwa teknologi robot ternyata cukup mendongkrak semangat siswa untuk belajar. Hal ini tidak menutup kemungkinan untuk membantu siswa untuk memahami pemrograman dengan bantuan robot di Indonesia. Telah terdapat penelitian (Jalil, 2016), untuk memanfaatkan robot sebagai media pembelajaran dengan membangun sebuah purwarupa robot humanoid.

Sistem robot cerdas humanoid merupakan model robot yang paling banyak digunakan di masa yang akan dating. Fitur terpenting dalam robot humanoid adalah mampu bergerak layaknya manusia. Perangkat keras untuk mengimplementasikan robot humanoid dari awal dapat dikatakan mahal, sehingga alih-alih kita dapat memodifikasi robot mainan Robosapien dari Wowwee untuk maksud ini (Samans, 2007). Selain itu fitur lainnya yang penting adalah dapat ditanamkan kecerdasarn buatan dalam robot humanoid tersebut (Budiharto et al, 2014, 2015). Untuk maksud tersebut, digunakan Raspberry Pi Zero W dalam penelitian ini agar dapat dikembangkan kemampuan kecerdasan buatan seperti melihat dan berbicara. Dengan menggunakan berbagai metode kecerdasan buatan pada robot humanoid, maka mampu menyelesaikan tugas sesuai dengan perintah yang diinginkan. (Ha, et al, 2011). Jadi kontribusi utama dalam penelitian ini adalah membangun robot humanoid dengan harga yang terjangkau, yang mampu ditanamkan berbagai metode kecerdasan.

Dalam penelitian sebelumnya (Tarunajaya, et al, 2016), kami mengembangkan robot humanoid yang dapat berinteraksi dengan mengenali wajah seseorang dan menjawab pertanyaan sederhana. Dilanjutkan lagi (Ngarianto, et al, 2018), robot humanoid telah ditanamkan metode untuk memisahkan dua sinyal suara yang berbeda yaitu laki-laki dan perempuan. Namun gerakan robot tersebut hanya dibagian tangan saja yang bergerak. Sedangkan dibagian kaki, gerakan robot yang kurang stabil dan sulit dikembangkan. Penelitian ini dilanjutkan kembali (Gunawan, et al, 2017), dimana robot humanoid Rapiro digunakan untuk mengenali dua suara yang berbeda dan memerintahkan robot mobil Rovio untuk mengantarkan pesanan seseorang ke lokasi tujuan. Untuk menanamkan kecerdasan buatan lebih lanjut, telah dilakukan penelitian (Gunawan, et al, 2018) agar robot humanoid Rapiro dapat melakukan tanya jawab untuk memecahkan soal aritmatika dalam Bahasa Indonesia.

Oleh karena itu, dalam makalah ini dikembangkan sistem kendali pergerakan robot humanoid yang dapat diimplementasikan dengan biaya yang terjangkau, akan tetapi dapat ditanamkan kecerdasan buatan di dalamnya. Untuk maksud ini digunakan robot mainan Robosapien sebagai basis perangkat keras dan Raspberry Pi Zero W sebagai mikroprosesor nya, serta bahasa pemograman Python untuk mengendalikan gerakan robot sesuai yang diinginkan. Robot humanoid yang dikembangkan harus dapat bergerak layaknya manusia seperti maju, mundur, melambaikan tangan, melakukan gerakan karate dan menari. Makalah ini disusun dengan menjelaskan pengembangan perangkat keras dan perangkat lunak dari robot humanoid. Selanjutnya akan dilakukan ujicoba pada robot yang telah dikembangkan terutama mengenai kendali gerakannya. Dan terakhir ditutup dengan kesimpulan dari proses pengembangan robot humanoid ini.

\section{METODOLOGI PENELITIAN}

\subsection{Arsitektur Robosapien}

Arsitektur Robosapien terdiri dari tujuh motor dan enam sensor sentuh (lihat Gambar 1). Terdapat satu motor di setiap bahu, satu di setiap siku (yang memutar lengan bawah dan membuat cakar membuka dan menutup), satu di pinggang, dan satu di setiap kaki. Robosapien tidak menggunakan servo tetapi menggunakan motor DC. Sedangkan sensor sentuh terdapat pada jari terpanjang di masing-masing tangan, dan dua di masing-masing kaki (satu di depan dan satu lagi di belakang). Robosapien juga memiliki sensor suara di dadanya, LED di setiap telapak tangan dan masing-masing mata, serta speaker di punggung belakang.

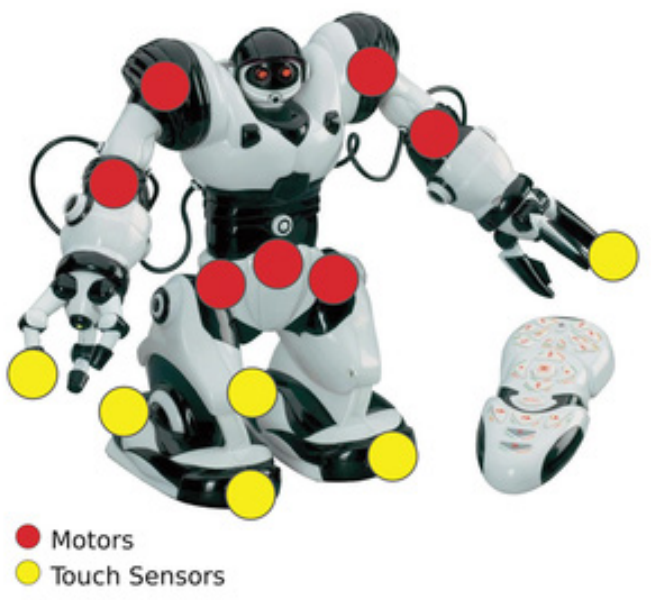

Gambar 1. Arsitektur dari Robosapien

Pada setiap kaki terdapat dua baterai besar tipe D yang memberikan Robosapien tidak hanya dengan daya, tetapi juga stabilitas. Jika baterai ini diganti dengan sumber daya lain yang ditempatkan di tempat lain, Robosapien dapat menjadi tidak stabil gerakannya dan kemungkinan besar baterai tersebut akan jatuh saat berjalan. Empat kali baterai $\mathrm{D}$ ini memberikan $6 \mathrm{v}$ untuk motor dan $3.3 \mathrm{v}$ untuk papan kontrol dan LED.

Dengan melepaskan sekrup di bagian belakang Robosapien, kita dapat membuka selubung belakang dan selubung depan. Setelah dibuka, dapat dilihat papan rangkaian bagian depan (lihat Gambar 2) dan papan rangkaian bagian belakang (lihat Gambar 3) dari Robosapien. Papan rangkaian bagian depan merupakan papan utama (motherboard), yang fungsinya dapat dilihat pada Gambar 4. 


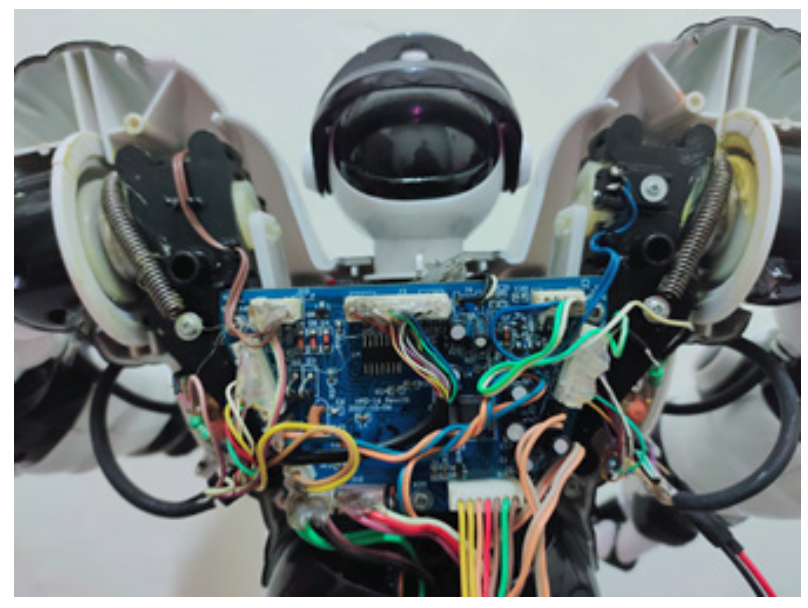

Gambar 2. Rangkaian bagian depan Robosapien

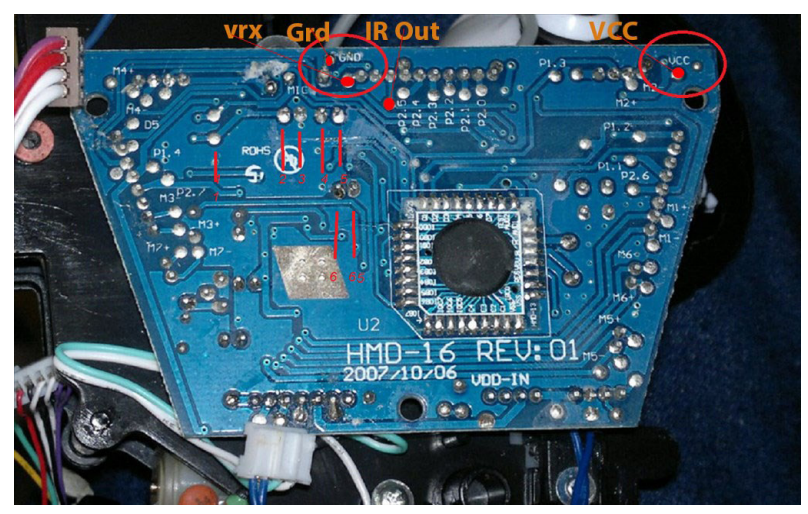

Gambar 3. Rangkaian bagian belakang Robosapien

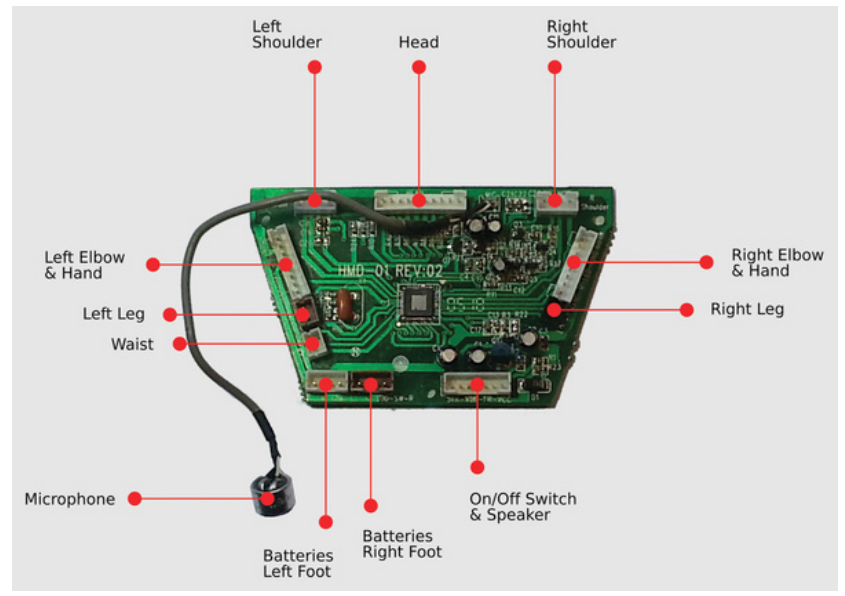

Gambar 4. Skema dari papan utama Robosapien

\subsection{Pengembangan Perangkat Keras}

Sebagai pengendali Robosapien digunakan mikroprosesor Raspberry Pi Zero W. Selanjutnya perlu dihubungkan dengan rangkaian bagian belakang Robosapien, yaitu pin IR Out dan pin Ground (lihat Gambar 3) dengan pin GPIO21 dan pin Ground pada Raspberry Pi Zero W secara berturut-turut. Selanjutnya sebagai sumber tegangan digunakan powerbank $5 \mathrm{v}$ yang dihubungkan ke power usb pada Raspberry Pi Zero W. Skema lengkap dapat dilihat pada gambar 5 di bawah ini. Selanjutnya papan rangkaian dari Robosapien diletakkan kembali pada tempat semula dan mikroprosesor Raspberry Pi Zero W diletakkan pada rongga dada dari Robosapien (lihat Gambar 6). Sedangkan powerbank diletakkan di luar selubung Robosapien yaitu pada punggung belakang (lihat Gambar 9).

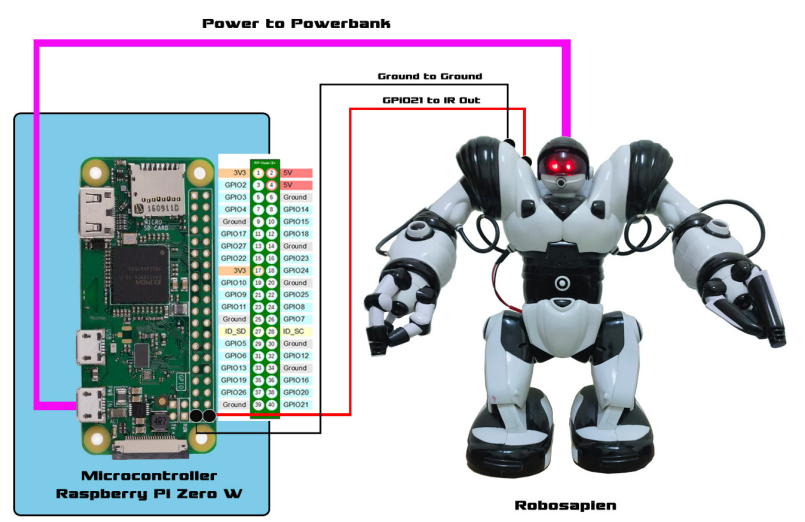

Gambar 5 Rangkaian Robosapien

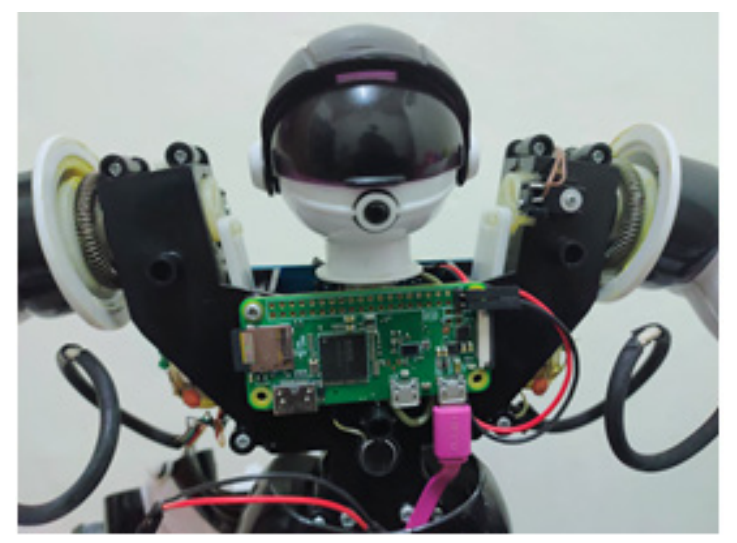

Gambar 6. Modul tambahan Raspberry Pi Zero W

\subsection{Pengembangan Perangkat Lunak}

Untuk mengembangkan perangkat lunak dari sistem pengendali robot Robosapien digunakan bahasa pemrograman Python. Selain itu digunakan pustaka PiGPIO mengendalikan pin General Input Input Output (GPIO) pada Raspberry Pi (Cicolani, 2018). Pustaka ini bekerja di semua versi dari Raspberry Pi. PiGPIO berjalan sebagai proses daemon di latar belakang, yang melakukan beberapa tugas tanpa intervensi dari pengguna. Secara singkat cara kerjanya dapat dijelaskan sebagai berikut:

1. Pertama kali, pin GPIO21 dikoneksikan dengan pin IR Out pada Robosapien dengan perintah:

pi.set_mode (21, pigpio.OUTPUT)

2. Pada pustaka PiGPIO, fungsi wave add generic () digunakan untuk membuat gelombang persegi yang diperlukan. Fungsi ini membutuhkan objek dengan tipe data list yaitu: pulse () dan juga tiga parameter yaitu: pin GPIO untuk diset tinggi, pin GPIO untuk diset rendah, dan waktu dalam mikrodetik. Dalam kode di bawah ini menunjukkan 
gelombang yang digunakan ketika bit diatur ke 1, yaitu: wf_hi dan ketika bitnya 0, yaitu: wf_lo. Untuk wf hi, pulsa pertama menyalakan pin selama 4 siklus, yang kedua mematikannya selama 1 siklus. Untuk wf_lo, pulsa pertama hanya untuk 1 siklus.

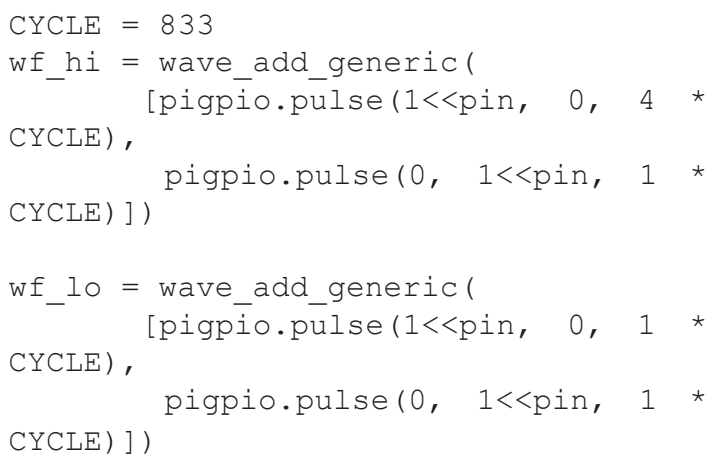

3. Selanjutnya diperlukan untuk mem-parsing kode perintah yang sedang dikirim (misalnya 0x82) dan mencari tahu bit biner mana yang aktif atau tidak aktif untuk membangun bentuk gelombang yang diperlukan. Untuk ini dibutuhkan sedikit operator untuk pergeseran. Berikut kode singkatnya:

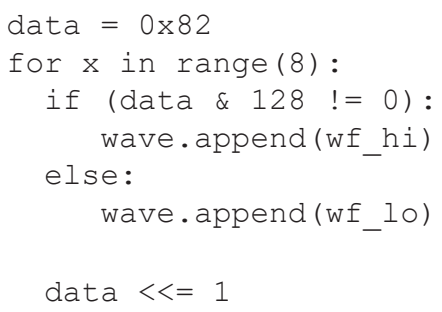

4. Terakhir semua kode dibungkus dalam sebuah kelas Robo, yang menyediakan fungsi send code (). Fungsi ini digunakan untuk mengirimkan nilai HEX, misalnya 0x82 untuk memutar pergelangan tangan kanan keluar. Berikut contoh penggunaannya:

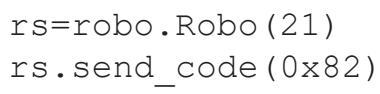

\subsection{Media Pembelajaran}

Selanjutnya untuk menggunakan Robosapien sebagai media pembelajaran perlu mengikuti alur kerja dalam bentuk flowchart pada Gambar 7 berikut ini:

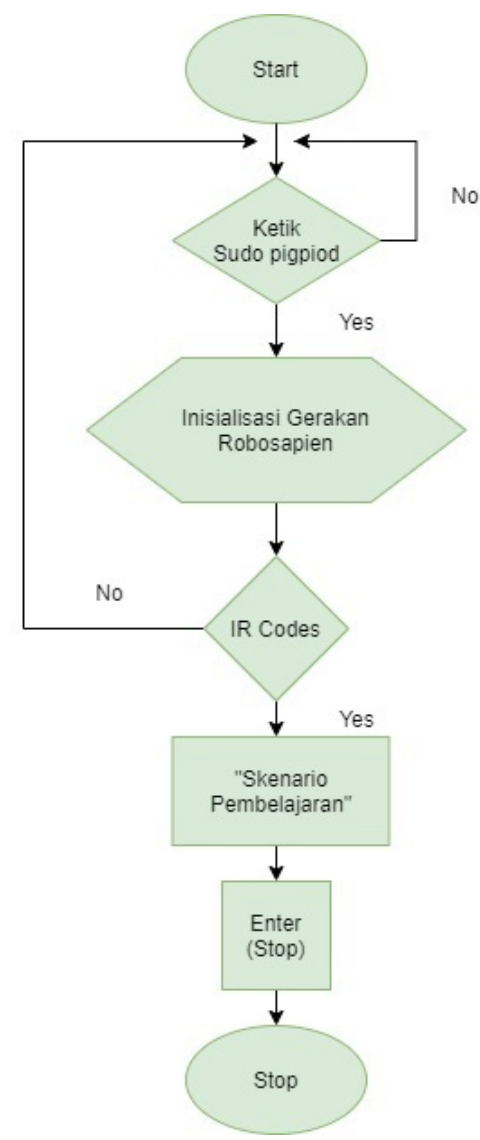

Gambar 7. Flowchart Robosapien

Secara singkat cara penggunaan Robosapien sebagai media pembelajaran dapat dijelaskan sebagai berikut:

- Pertama dimulai dari Start untuk menjalankan sebuah program dengan mengetik "sudo pigpiod" agar proses Daemon untuk pin GPIO dapat berjalan

- $\quad$ Setelah itu menginisiasi koneksi antara pin GPIO21 di Raspberry Pi dengan pin pin IR Out pada Robo sapien dengan perintah "rs=robo.Robo(21)".

- Setelah itu siswa dapat diminta merancang sebuah gerakan sesuai skenario pembelajaran, misalnya gerakan untuk berjalan ke suatu tempat. Rancangan tersebut akan berupa IR Code (lihat Tabel 1) mengunakan bahasa pemograman Python.

- Selanjutnya siswa dapat mengevaluasi skenario pembelajaran tersebut dengan menjalankan skrip yang telah dibuat.

- Untuk memberhentikan gerakan dapat menekan tombol enter. Gerakan Robosapien otomatis akan berhenti dengan sendirinya.

Jadi metode yang dikembangkan untuk mempelajari pemrograman dengan robot humanoid (Kurebayashi, et al, 2006) adalah dengan memberikan skenario pembelajaran yang berupa aktifitas robot yang harus diselesaikan. Siswa kemudian diminta untuk mendesain gerakan robot Robosapien (lihat Gambar 8) berdasarkan Tabel 1, yang sesuai untuk menyelesaikan skenario pembelajaran ini. Dan terakhir siswa dapat langsung mengevaluasi langsung hasil dari desain yang dibuat dalam bahasa pemrograman Python. 
Dengan cara ini, siswa dapat belajar untuk melihat efek dari kodenya secara langsung dan dapat segera memperbaikinya jika output tidak sesuai dengan yang diinginkan. Jika siswa tersebut dapat menyelesaikan semua skenario pembelajaran yang diberikan maka dapat dinyatakan lulus ujian praktek.

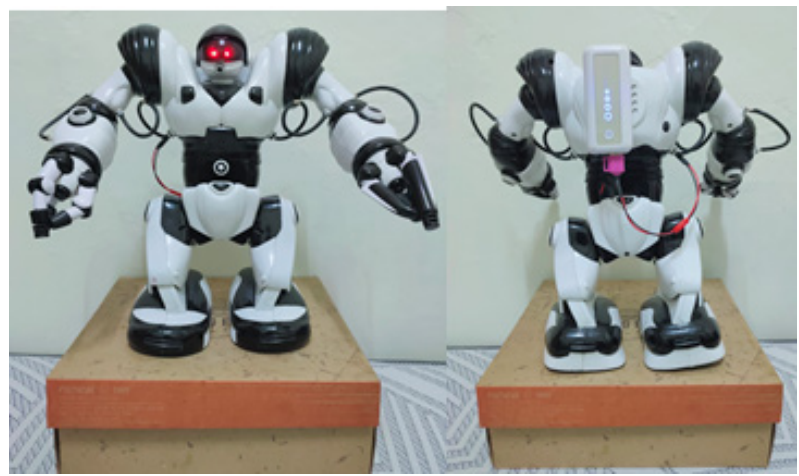

Gambar 8. Robosapien

Dalam Tabel 1 dibawah ini berisi Kode dan Gerakan yang akan dilakukan oleh Robosapien. Siswa dapat menyelesaikan skenario pembelajaran dengan mengkombinarikan Kode tersebut dengan mengunakan pemograman python.

Tabel 1. Perintah Gerakan Robosapien

\begin{tabular}{|c|c|}
\hline Kode & Gerakan \\
\hline$\$ 80$ & turn right (on left side of remote) \\
\hline$\$ 81$ & right arm up (upper left button on remote) \\
\hline$\$ 82$ & right arm out \\
\hline$\$ 83$ & tilt body right \\
\hline$\$ 84$ & right arm down \\
\hline$\$ 85$ & right arm in \\
\hline$\$ 86$ & walk forward \\
\hline$\$ 87$ & walk backward \\
\hline$\$ 88$ & turn left (on right side of remote) \\
\hline$\$ 89$ & left arm up (upper right button on remote) \\
\hline$\$ 8 \mathrm{~A}$ & left arm out \\
\hline$\$ 8 \mathrm{~B}$ & tilt body left \\
\hline$\$ 8 \mathrm{C}$ & left arm down \\
\hline$\$ 8 \mathrm{D}$ & left arm in \\
\hline$\$ 8 \mathrm{E}$ & stop \\
\hline$\$ C C$ & talkback \\
\hline \$D2 & Demo 1 (Karate skits) \\
\hline \$D4 & Dance \\
\hline
\end{tabular}

\section{HASIL DAN PEMBAHASAN}

Untuk mengendalikan Robosapien, perlu dilakukan langkah-langkah sebagai berikut ini:

1. Tekan tombol power Robosapien, sampai robot tersebut bersuara dengan mengangkat ke dua tangan keatas.

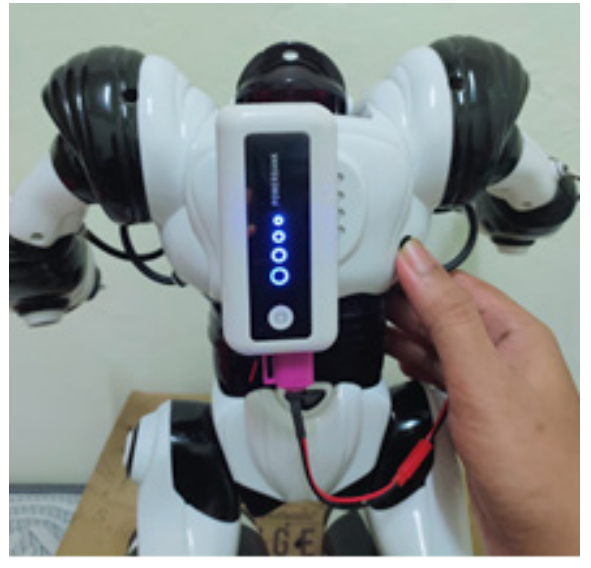

Gambar 9. Menghidupkan Robosapien

2. Jalankan Perintah Remote Desktop di Komputer atau Laptop melalui RUN kemudian ketik mstsc. Terlihat gambar 10 .

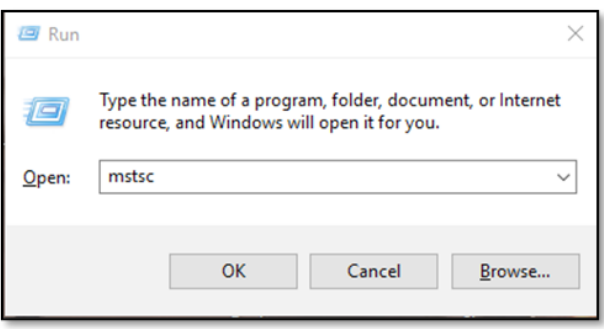

Gambar 10. Perintah remote desktop

3. Setelah di OK akan muncul tampilan Remote Desktop, dan ketik alamat IP addrees yang ada di raspberry pi zero w pada robosapien. Terlihat gambar 11.

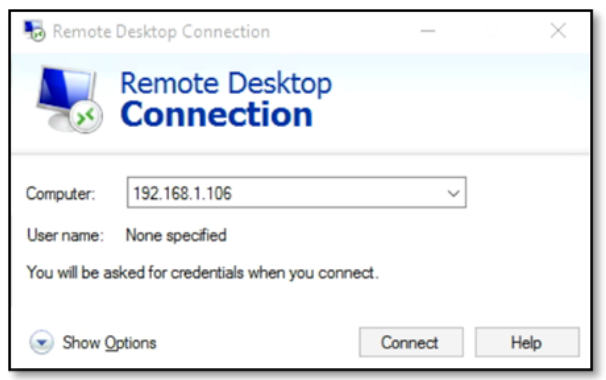

Gambar 11. IP Address Robosapien

4. Selanjutnya buka terminal terlihat gambar 12. Ketik sudo pigpiod. Jalankan program python Robosapien yang terletak pada folder Robosapien. Dengan mengetik python test.py. 


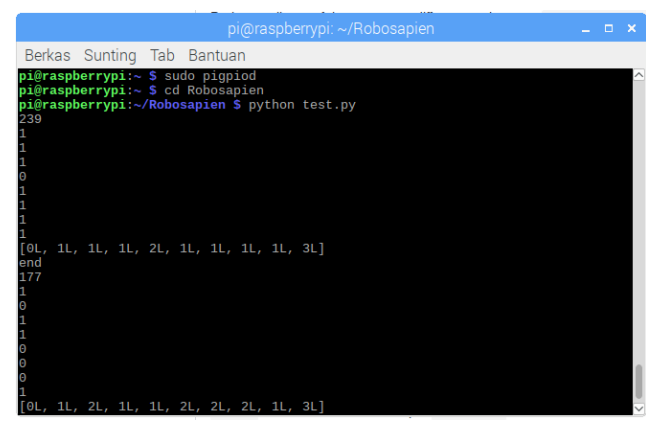

Gambar 12. Menjalankan Robosapien

5. Gambar 13 adalah tampilan keselururuhan Robosapien.

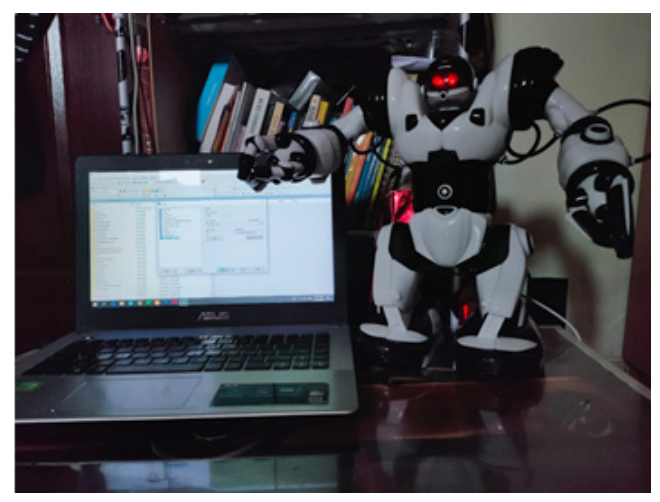

Gambar 13. Menjalankan Robosapien

\section{KESIMPULAN}

Dalam makalah ini telah berhasil dibangun sistem kendali pergerakan robot humanoid. Sistem kendali ini menggunakan modul Raspberry Pi Zero W sehingga dapat digunakan secara nirkabel, selain dapat ditanamkan kecerdasan buatan di dalamnya. Sistem ini dapat diimplementasikan dengan biaya yang terjangkau karena menggunakan perangkat keras berupa robot mainan Robosapien yang cukup murah. Dengan menggunakan sistem ini, siswa dapat belajar pemrograman melalui media pembelajaran robot humanoid. Siswa dapat diminta untuk menyelesaikan suatu skenaro pembelajaran dengan mendesain gerakan robot yang sesuai. Dari eksperimen yang dilakukan, dapat diamati siswa menjadi bersemangat belajar pemrograman melalui interaksi langsung dengan Robosapien. Menyelesaikan suatu skenario pembelajaran, menurut siswamerupakanhalyang sulittetapimenyenangkan dapat diwujudkan dengan mendesain gerakan robot ke dalam kode program. Dengan demikian kami yakin akan efek pembelajaran melalui media robot humanoid untuk memperkuat motivasi siswa dalam belajar pemrograman.

\section{DAFTAR PUSTAKA}

Budiharto, W., Kanigoro, B., \& Noviantri, V. (2014). Ball Distance Estimation and Tracking System of Humanoid Soccer Robot, 170-178.
Budiharto, W., Gunawan, A. A., Sari, A. C., \& Ngarianto, H. (2015). Designing of Humanoid Robot with Voice Recognition Capability. In Proceedings of the 3rd IIAE International Conference on Intelligent Systems and Image Processing (pp. 202205).

Cicolani, J. (2018). Raspberry Pi GPIO. In Beginning Robotics with Raspberry Pi and Arduino (pp. 103128). Apress, Berkeley, CA.

Gunawan, A. A., Stevelino, A., Ngarianto, H., Budiharto, W., \& Wongso, R. (2017). Implementation of Blind Speech Separation for Intelligent Humanoid Robot using DUET Method. Procedia computer science, 116, 87-98.

Gunawan, A. A., Mulyono, P. R., \& Budiharto, W. (2018). Indonesian Question Answering System for Solving Arithmetic Word Problems on Intelligent Humanoid Robot. Procedia Computer Science, 135, 719-726.

Ha, I., Tamura, Y., Asama, H., Han, J., \& Hong, D. W. (2011). Development of Open Humanoid Platform DARwIn-OP, 2178-2181.

Jalil, A. (2016). Rancang Bangun Robot Humanoid. Proceeding, Konferensi Nasional Ilmu Komputer (KONIK APTIKOM), ISSN, 2338-2899.

Kurebayashi, S., Kamada, T., \& Kanemune, S. (2006, November). Learning computer programming with autonomous robots. International Conference on Informatics in Secondary Schools-Evolution and Perspectives (pp. 138-149). Springer, Berlin, Heidelberg.

Major, L., Kyriacou, T., \& Brereton, O. P. (2012). Systematic literature review: teaching novices programming using robots. IET software, 6(6), 502-513.

Miller, D. P., \& Nourbakhsh, I. (2016). Robotics for education. In Springer handbook of robotics (pp. 21152134). Springer, Cham.

Ngarianto, H., Gunawan, A. A., \& Budiharto, W. (2018). Separating Multi Speeches in Intelligent Humanoid Robot using FastICA. IPTEK The Journal for Technology and Science, 29(1), 1-4.

Ospennikovaa, E., Ershovb, M., \& Iljin, I. (2015). Educational robotics as an inovative educational technology. Procedia-Social and Behavioral Sciences, 214, 18-26.

Pandey, A. K., \& Gelin, R. (2017). Humanoid robots in education: a short review. Humanoid robotics: a reference, 1-16.

Samans, J. (2007). The Robosapien Companion: Tips, Tricks, and Hacks. Apress.

Tarunajaya, C., Oey, K. W., Kuwandy, R. L., Ngarianto, H., Gunawan, A. A., \& Budiharto, W. (2016). Designing of Medium-Size Humanoid Robot with Face Recognition Features. IPTEK The Journal for Technology and Science, 26(2). 